\title{
Analysis of puzzle shaped continuous shear connector
}

\author{
P. Vaňová, R. Kanishchev \& V. Kvočák \\ Technical University of Košice, Košice, Slovakia
}

\begin{abstract}
Continuous shear connectors are a recent invention, from a bridge science point of view as the first one was patented in 1985 by W. Andrä after spare of general interest in this area after the end of World War II. Therefore their development is now still hugely a focus of many researchers. At Technical University of Košice, Faculty of Civil Engineering, new geometrical characteristics of puzzle shaped steel perforated strip were designed. The strip underwent several tests, in which it was closely observed and measured, specifically the push-out tests as well as the bending tests. Both materials, steel and concrete, also underwent testing to find out their exact material characteristics for precise analysis input data along with FEM analysis later in the research. The results were analysed and are presented in this paper together with the geometrical, material and testing process description.
\end{abstract}

\section{INTRODUCTION}

Several authors contributed to this area of study. Firstly, Oguejiofor and Hosain were amongst the first researchers to publish a study of FEM analysis of continuous shear connectors at the end of last century (Oguejiofor \& Hosain, 1993). From nowadays researches, Lorenc et al. did a comprehensive study of dowel shape (Lorenc, 2009, 2016); Classen and Hegger researched the pry-out failure of concrete in specimens with dowel connectors (Classen \& Hegger, 2017).

\section{SHAPE}

As the title suggests, the proposed perforated strip is of a puzzle shape. In the Figure 1, the dimensions of one tooth are shown. Its shape was carefully design to spread the stress with the geometrical advantage being a possibility to produce two identical shapes out of one I-beam by cutting it into two equal longitudinal halves.

Firstly, the cross-section of the composite beam was being considered and tested as a rectangle - the shear connectors being simply poured into a concrete block. However, this design consisted unnecessary parts, where tension in concrete was present. For this very reason, those parts were missed out of the following testing, to make even more effective design, which is still easy to prefabricate. The new design of the cross-section is shown in the Figure 2.

\section{MATERIALS}

The tested specimens were manufactured from two basic materials: steel and concrete. Material characteristics were established from series of testing the materials underwent. 


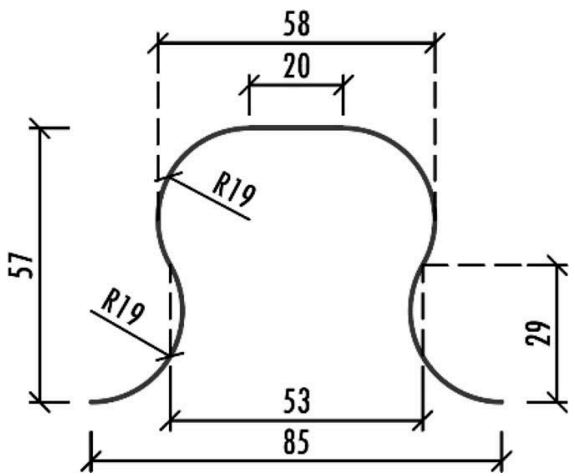

Figure 1. The exact shape of one puzzle tooth.



Figure 2. Dimensions of lightened beam in cross-section.

\subsection{Concrete}

European quality concrete C30/37 was used. The necessary tests performed on one year old specimens at Laboratory of Excellent Research:

- The compressive tests of cubes, beams and cylinders of standardized dimensions; measured with calliper beforehand;

- The four-point flexural tests onto beams;

- The Young's Modulus tests;

- The tensile tests.

Material characteristics included in FEM analysis are summarized in the following Table 1.

Table 1. Properties of concrete.

\begin{tabular}{lll}
\hline Characteristic & Measured value & Unit \\
\hline Mass density & $2.274 \mathrm{E}-09$ & tonnel $\mathrm{mm}^{3}$ \\
Young's Modulus & 33423.8 & $\mathrm{MPa}$ \\
Poisson's ratio & 0.2 & - \\
Tensile Strenght & 6.89 & $\mathrm{MPa}$ \\
Compressive Strenght & 66.31 & $\mathrm{MPa}$ \\
\hline
\end{tabular}




\subsection{Steel}

Steel used for the connector was tested by Faculty of Metallurgy. They performed tensile tests to determine Yield point of the material, results are visible in Figure 3. Other values were taken from normative characteristics, summarized in the Table 2.

\subsection{Reinforcement}

Reinforcement used in the experiments were not tested, therefore in any further numerical study the norm characteristics were considered. The bars were of $12 \mathrm{~mm}$ diameter, with european label B500.

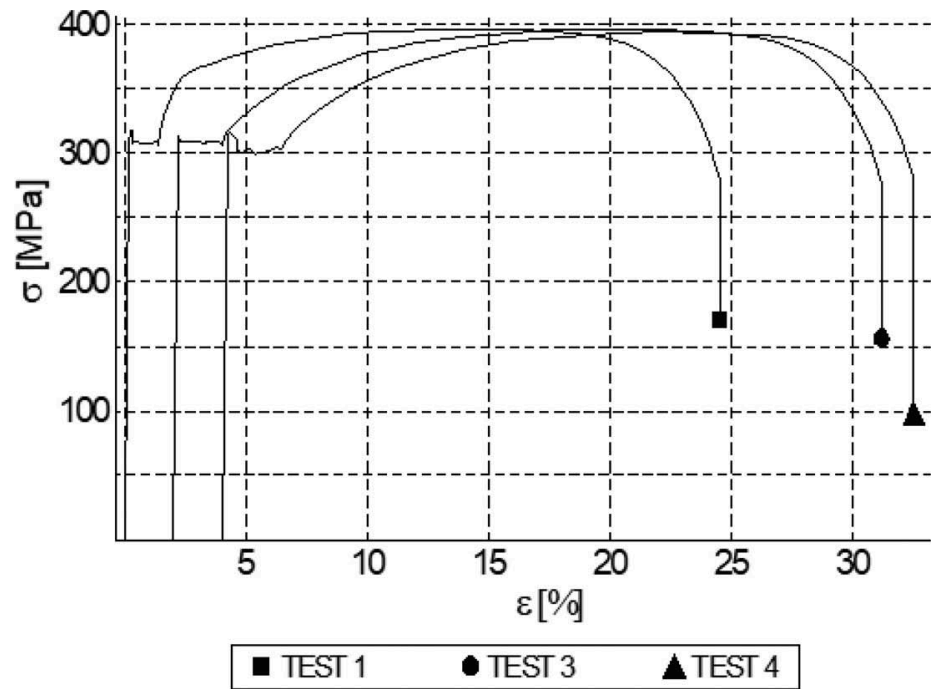

Figure 3. Diagrams of three steel samples tested.

Table 2. Properties of steel.

\begin{tabular}{lll}
\hline Characteristic & Measured value & Unit \\
\hline Mass density & $8.654 \mathrm{E}-09$ & tonnelmm \\
Young's Modulus & 210000 & $\mathrm{MPa}$ \\
Poisson's ratio & 0.3 & - \\
Yield point & 315.3 & $\mathrm{MPa}$ \\
\hline
\end{tabular}

Table 3. Properties of reinforcement.

\begin{tabular}{lll}
\hline Characteristic & Measured value & Unit \\
\hline Mass density & $8.65 \mathrm{E}-09$ & tonnelmm \\
Young's Modulus & 210000 & $M P a$ \\
Poisson's ratio & 0.3 & - \\
Yield point & 490 & $M P a$ \\
\hline
\end{tabular}




\section{EXPERIMENTAL PROGRAMME}

Two experiments were performed onto three specimens each, to determine the shear and bending resistance of the composite connection. They are described in the following sub-chapters.

\section{$4.1 \quad$ Push-out test}

Four specimens were made in order to find out the shear resistance of the puzzle shaped continuous shear connector via push-out tests. Two connectors connected with steel plate were poured into two $200 \times 600 \times 600 \mathrm{~mm}$ concrete blocks and put into hydraulic press, which loaded the specimens during 99 loading conditions. Slip was measured by inductive displacement sensors placed on both sides of the middle steel plate. The results recorded are presented in Fihure 4.

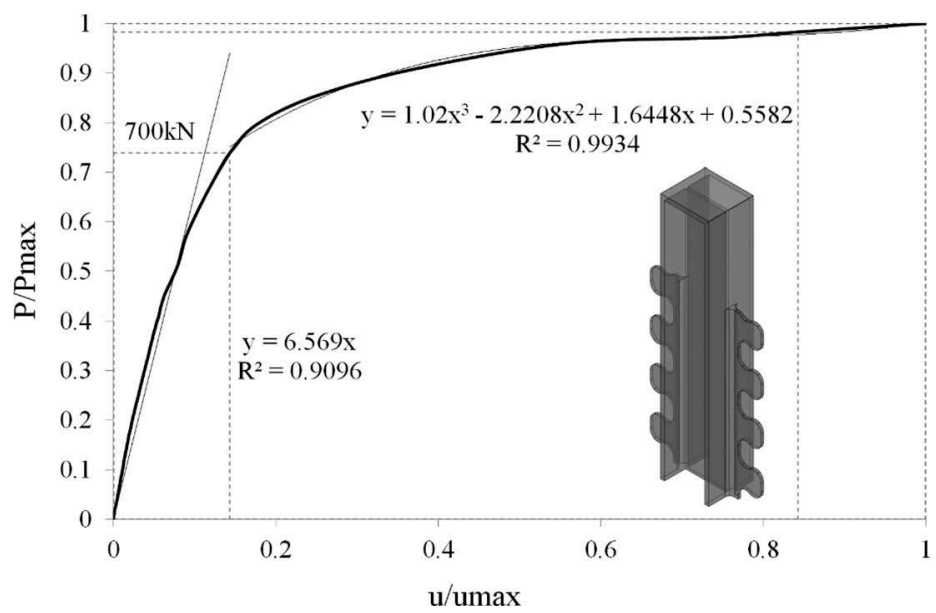

Figure 4. Diagram of the push-out tests results.

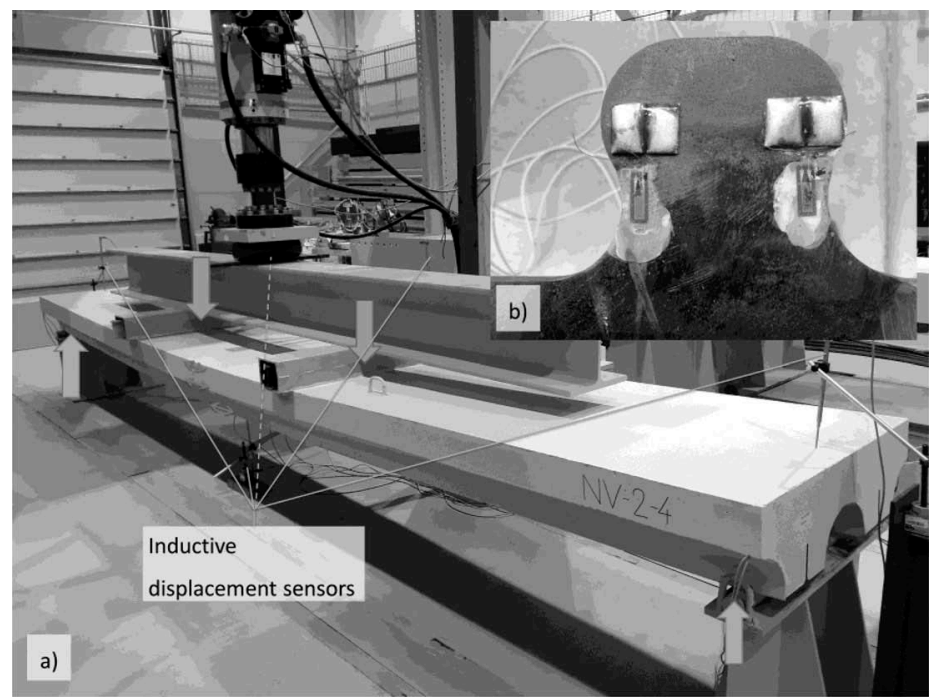

Figure 5. Four-point flexural test: a) the overall layout of the test; b) strain gauges application on the tooth of the strip. 


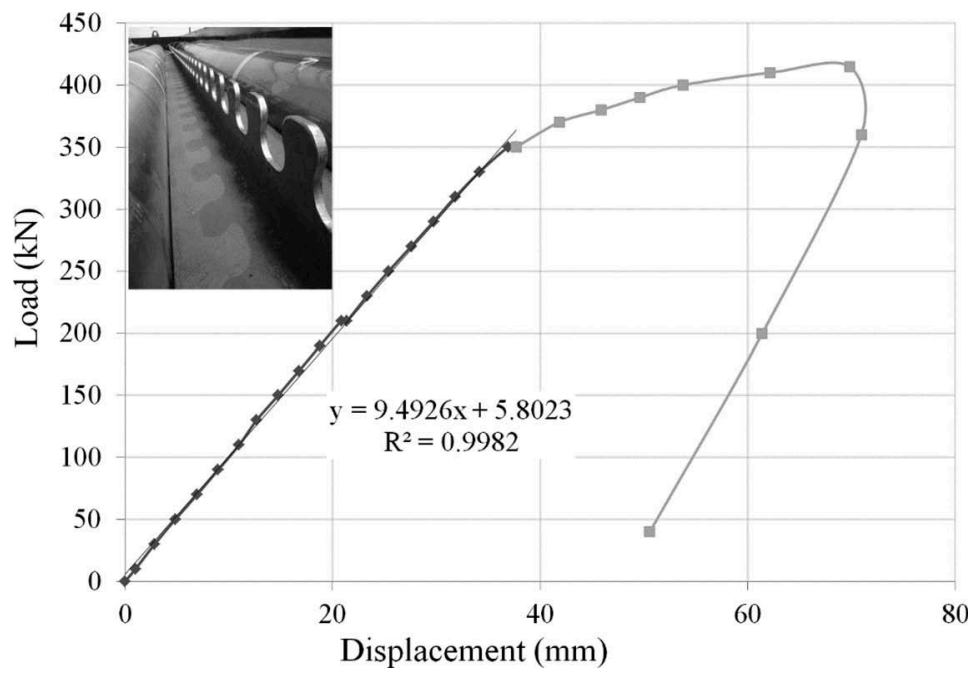

Figure 6. Diagram of the four-point flexural tests results.

The first part of the diagram shows linear behaviour of the specimens, at the end of which the shear resistance was determined. The loading condition was at the value of $700 \mathrm{kN}$ at that point. Afterwards, the specimens started to develop bigger slip, which is visible in the second, horizontal part of the graph. In the third part, the slip started growing uncontrollably, and the tests were stopped.

\subsection{Four-point flexural test}

Four-point flexural tests were performed on three $6 \mathrm{~m}$ long lightened beams that included two rows of connectors. Two support were located $100 \mathrm{~mm}$ from the beams ends and two loads forces were applicated approximately $900 \mathrm{~mm}$ from the center of the beam.

During the loading process, two loading cycles were done to prove the linear behaviour of the specimens.

In the Figure 6, the results are shown. The end of the linear part was determined to be at the point of $350 \mathrm{kN}$, which equals the bending resistance of the specimens.

\section{NUMERICAL PROGRAMME}

Finite element model was created to simulate the four-point flexural test. The analysis was developed in Abaqus/CAE software.

Dynamic, Implicit step was chosen for the analysis. General contact was included, with 0.93 coefficient of friction in-between the surfaces of steel dowel and concrete. Both loading cycles were also included. The loading conditions were the exact copy of the loading conditions set in experiments. The specimen was meshed by C3D4 element for concrete and steel, described as 4-node linear tetrahedrons (see Figure 7).

As visible in Figure 8, the first loading cycle acted as expected. The second one, on the other hand, presented with slightly bigger displacement changes, which might by caused by insufficiently accurate material properties of concrete.

The bending resistance from software was a little higher with ratio of 1.06 at $370 \mathrm{kN}$. However, the deviation was lower during every loading condition, except first and last, and the average deviation was $20.49 \%$. 


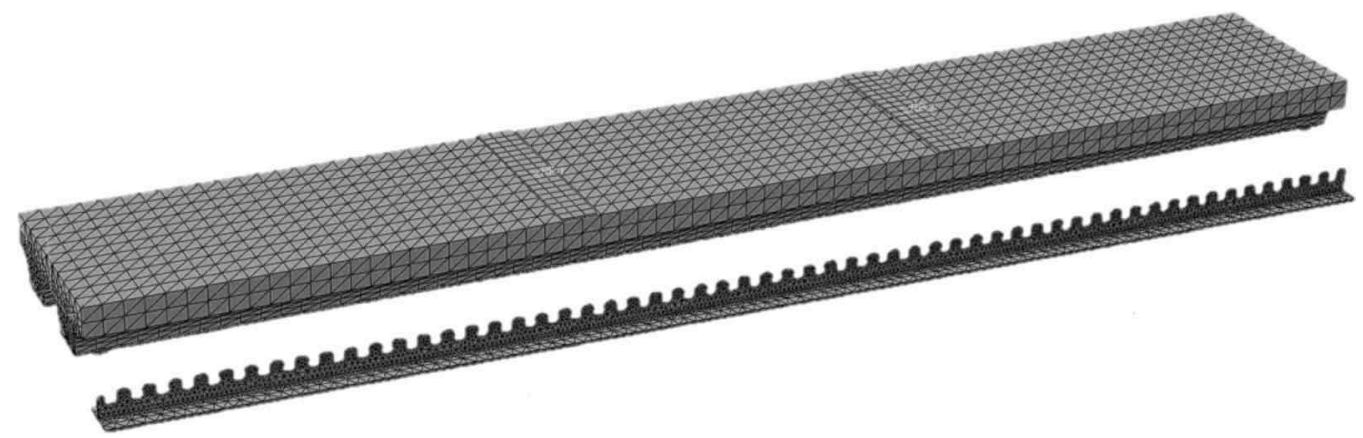

Figure 7. Mesh of the four-point flexural test modeled in Abaqus/CAE.

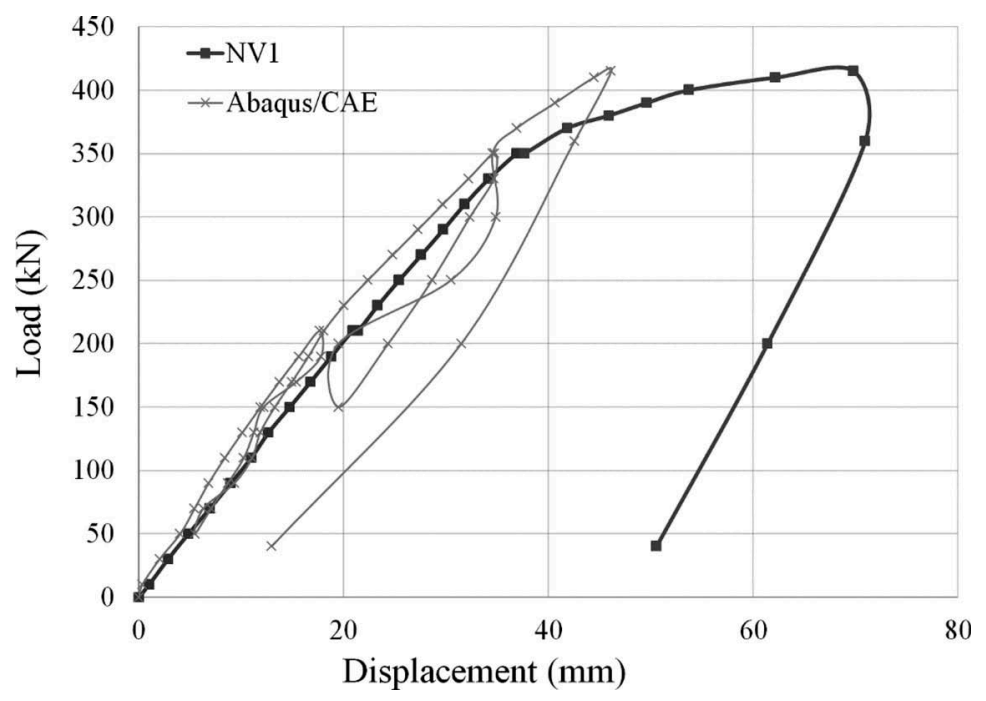

Figure 8. Results from Abaqus software compared with experimental results.

\section{CONCLUSION}

In conclusion, the experiments proved the eligibility of the puzzle shaped continuous shear connectors as well as of the lightened beams cross-section for the usage for short-span bridges in practice.

The FEM analysis was also successfully with deviation mentioned above, it is suitable for the further parametric study.

\section{REFERENCES}

Classen, M. and Hegger, J. 2017. Shear-slip behaviour and ductility of composite dowel connectors withpry-out failure. Engineering Structures 150: 428-437.

Lorenc, W. 2009. Boundary approach in shape study of composite dowel shear connector. Archives of Civil and Mechanical Engineering 9: 55-66.

Lorenc, W. 2016. The design concept for the steel part of a composite dowel shear connection. Steel Construction 9(2): 89-97.

Oguejiofor, E. C. and Hosain, M. U. 1997. Numerical analysis of push-out specimens with perfobond rib connectors. Computers and Structures 62: 617-624. 